\title{
¿A mayor peso más alergias?
}

\section{Erin E. Dooley}

$\mathrm{U}$ n estudio financiado conjuntamente por el NIEHS [Instituto Nacional de Ciencias de Salud Ambiental] y el NIAID [Instituto Nacional de Alergias y Enfermedades Infecciosas], ambos de los Estados Unidos, sugiere una posible conexión entre el incremento de los índices de obesidad infantil y las alergias en las últimas décadas. Tras analizar los datos de la encuesta NHANES de los años 2005 y 2006, los investigadores reportaron en el número de mayo de 2009 del Journal of Allergy and Clinical Immunology que los niños obesos presentaban una tendencia mayor en $26 \%$ a padecer alergias que los niños de peso normal, y en $59 \%$ a sufrir de alergias a ciertos alimentos. Los investigadores sostienen que, si bien este incremento en el riesgo de alergias puede no ser el problema de salud más grave que enfrentan los niños con sobrepeso, ciertamente proporciona un incentivo adicional para redoblar los esfuerzos encaminados a prevenir la obesidad infantil.

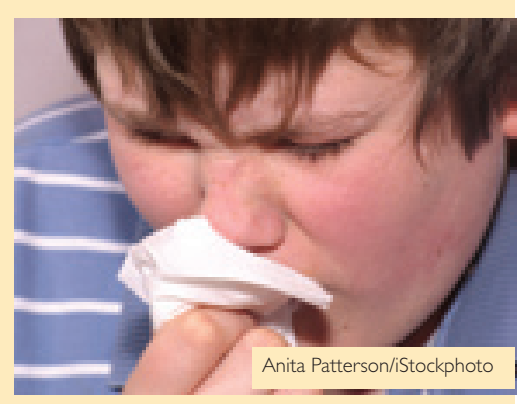

* Publicado originalmente en Environmental Health Perspectives, volumen 117, número 6, junio 2009, página A242. 